\title{
The Machine as Myth
}

\author{
Andreas Broeckmann \\ Leuphana University \\ Lüneburg, Germany \\ broeckmann@leuphana.de
}

\begin{abstract}
The essay argues that the notion of the machine should be understood as a mythological concept that is used to frame the cultural understanding of technics in the modern era. The author outlines the diversity of understandings of the term "machine" and shows how the same narrative core underwrites virually all modern references to the machine: a human-made technical system that increasingly gains autonomy and becomes an existential, though non-lethal threat for humans. The text proposes to investigate works of twentieth-century "machine art" in order to arrive at alternative readings of the relationship between humans and technics.
\end{abstract}

Machine. Myth. Machine Art. Technology. Art History. Max Dean. Seiko Mikami.

\section{INTRODUCTION}

Placing a word or an expression between quotation marks interrupts the flow of the text and signifies a change of register, or a change of the level at which the text operates. The word at once appears like a quotation that is built into a sentence, taken from some other text, and that thus creates an intersection of different texts and their contexts.

This essay encourages its readers to put the word machine between quotation marks - when they see or hear it, and maybe even when they use it themselves. Putting the machine between quotation marks suggests that the concept comes from a context other than we habitually think. The text from which the word "machine" comes is a mythological text, a myth about humans and technics. It is a modern myth, one that is probably not much more than two centuries old - as old, I presume, as the notion of "man" whose emergence around the year 1800, Michel Foucault has described in The Order of Things (1966/1970). The modern human and the modern machine are companions, and both might also disappear again, together, - getting "erased, like a face drawn in sand at the edge of the sea," as Foucault writes in a famous passage at the end of his book (Foucault 1970:387). Today's theorists of the posthuman imagine the necessary end of a modernist understanding of the "human"; if we want to take this posthumanist plea seriously, we will also have to let go of a modernist, technological, and andrological understanding of the "machine".
In most usages of the word machine, the quotation marks that should really be there, have been removed, slipping the word into the text so as though it belonged there and as though there was no switching of contexts. As an element of the "ideology" of modern technology the mythological term "machine" is integrated into the flow of speech and written text, normalising, even naturalising the mythical relationship of human and technics that this concept serves to construct. What it does, first and foremost, is an affective black-boxing of technology.

The double challenge for a contemporary and emancipatory approach to technology is to build an understanding of technics that is not predicated on the binary opposition of human and machine, and to imagine, design and engineer an understanding of subjectivity that is not simply in submission towards the ideological regimes of the techno-logos.

\section{THE MACHINE IN ART}

The exemplary field of "machine art" enables us to approach a more general characterisation of machines. The robotic installation As Yet Untitled (1992-1995) by the Canadian artist Max Dean, for instance, is a technical apparatus that can operate without human intervention, while offering an interface for a possible interaction by the gallery visitor. (Broeckmann 2016) In this artwork, an industrial robot picks up a printed photograph from a stack, holds it up in order to display it to a potential audience for a moment, and then inserts the photograph into an electrical paper shredder. 
The photographs in the stack - found pictures that must have had a personal meaning for someone, at some point - are thus destroyed one by one. The exhibition visitor can interrupt this procedure by placing the palms of his or her hands at an interface in the shape of two hands, upon which the photograph currently processed is placed into a repository box and kept.

The snapshots' emotional potential, combined with the possibility of an intervention which will prevent the destruction of a commemorative souvenir, form the aesthetic core of Dean's installation. As Yet Untitled constructs the relation of human and machine as a dichotomous structure in which the machine usually functions repetitively and automatically, disregarding the emotional impact of its operation. In contrast, Dean's work posits the gallery visitor as a subjective agent who can take a decision and who can perform an action that will preserve a symbol of human memory and empathy. Even in the face of such obviously machine-related works, we have reason to use the genre term "machine art" with some hesitation only. In the history of modern and contemporary art, there are merely very few instances where this term has actually been used affirmatively - beyond that, "machine art" seems to be more of a rumour than an established historical fact.

However, one of the things that characterise the artistic discourse on machines, is a small, recurring number of tropes associated with the machine as a cultural actor. They are:

the machine as monster; the machine as creative force; and the machine as a replacement of humans (or as an ontological alternative).

These tropes also feature in three of the most poignant instances of the machine art discourse. (Broeckmann 2016) The first of these is an article by the art critic Konstantin Umanskij who, writing in 1920 about Vladimir Tatlin's counter-reliefs and material assemblages, inspired the Berlin Dadaists to coin their famous slogan, "Art is dead. Long live Tatlin's new machine art." Umanskij writes:

[Tatlin's] art of the machine ... regards no type of material as unworthy for art. Wood, glass, paper, sheet metal, iron, screws, nails, electrical appliances, glass splinters for sprinkling the surfaces, the mobility of individual parts of the work, etc. - all these are declared as legitimate means of the language of art, and its new grammar and aesthetics demand of the artist a broader technical training and a closer bond with his powerful ally - the grand machine.
Here the notion of the "ally" ties the human artist to an apparatus that appears as imposing and scary, "the grand machine".

This image of an intimate and scary opponent is also called up by Alfred $\mathrm{H}$. Barr who, together with the architect Philip Johnson, curated an exhibition entitled "Machine Art" at the Museum of Modern Art in New York in 1934 (Marshall 2012). The show presented objects from US-American industrial design, objects which were made in industrial contexts and whose form and materiality were determined by their functions. In his catalogue text, Barr revelled in the provocation of instances of formal beauty achieved without the intervention of human creativity, or artistic intention.

[Historically, it] is in part through the aesthetic appreciation of natural forms that man has carried on his spiritual conquest of nature's hostile chaos. Today man is lost in the far more treacherous wilderness of industrial and commercial civilization. On every hand machines literally multiply our difficulties and point our doom. If ... we are to 'end the divorce' between our industry and our culture we must assimilate the machine aesthetically as well as economically. Not only must we bind Frankenstein - but we must make him beautiful.

In this passage, the relationship set up is not an "alliance", but the vision of a marriage, threatened by divorce, a relationship that appears both necessary, and worrisome. The result of human engineering - Umanskij's "grand machine", Barr's "Frankenstein", representing the "treacherous wilderness of industrial and commercial civilization" - has to be bound and, at the same time, aestheticised, or perhaps, bound and tamed through aestheticisation.

We are here at the centre, a degré zéro of twentieth-century machine art. It is therefore not surprising that we hear a third major proponent of an art of machines, the Italian third-generation futurist Bruno Munari, exclaim in his Manifesto of Machinism (1938/1952):

The machine of today is a monster! The machine must become a work of art! We shall discover the art of machines!"

The same both critical and zestful attitude can befound in Jean Tinguely's purposeless hardware contraptions - supposedly inspired directly by Munari's Manifesto and his own macchine inutile sculptures. Both Munari's and Tinguely's kinetic sculptures are playful, perhaps somewhat atavistic rejections of a technological paradigm that, by the 1950s, was beginning to change the conditions under which human subjectivity and artistic creation were conceptualised. 
Some decades earlier, around 1920, artists like Francis Picabia and Marcel Duchamp had explored machines not so much from their sculptural and kinetic perspective, but with regard to their functional and symbolical dimensions. Both Picabia's mechanomorphic paintings and Duchamp's Large Glass point to the imaginary operation of machines - not only as technical items, but also as visualisations of psychological and sociological conditions which saw the import of mythological machine thinking into the cultural imaginary (Reck \& Szeemann 1999). These are not technically functional machines, but symbolical articulations of the way in which inter-human relations are structured - in the mimetic image of fantastic mechanical devices.

\section{TWENTIETH-CENTURY MACHINE TYPES}

Such a diversity of meanings is not only characteristic of the notion of the machine in art, but of the machine in general. Twentieth-century theorists have variably refered to the machine as a technical appliance that assumes a form of autonomy from its human creator (Gotthard Günther's "first" machine), as a "transclassical" or "cybernetic machine" that has no moving parts, "but conducts and 'critically' steers work procedures"; as the "Mega-Machine", alternatively referred to as machinery, apparatus, or state machine (Lewis Mumford, Karl Marx, Louis Althusser); the Turing Machine, i.e. the machine of mathematical calculations and algorithms (Alan Turing); and the abstract and autopoietic machines of heterogenesis and desire (Gilles Deleuze and Félix Guattari, following Humberto Maturana and Francisco Varela) (Broeckmann 2016).

A "machine" is not a particular type of device or conceptual mechanism with some specific technical features. If this were the case, the use of the term would be so chaotic and unreliable that it would be more or less redundant. However, people speak of machines with so much insistence and passion that there seems to be something particular that they want to express.

What unites all of these treatments of the modern machine is the trope of human-machine companionship. Whether we look at nineteenthcentury political theorist Karl Marx or science historian Georges Canguilhem, or at the father of cybernetics, Norbert Wiener, or at German cultural historian Martin Burckhardt's comprehensive study of the cultural history of the "spirit of the machine," (1999) - in each of these the direct and necessary coupling and companionship of human and machine are evident. In fact, the concept of the "machine" is always deployed in contrast to the human. Whereas "technics" exists independent of the human, "the machine" is invariably coupled to "man." Two aspects are therefore constitutive for the notion of the machine: its coupling to the figure of the human, and its conception as a condition of modern human self-definition.

A more precise definition of the notion of the machine can be developed in analogy to the understanding of the conception of the "apparatus" as it has been proposed by the Italian philosopher Giorgio Agamben with reference to Foucault's conception of the dispositif (Agamben 2009). In his explanation, Agamben suggests a diagrammatic relation between apparatuses, living beings, and subjects. Agamben writes: "I shall call an apparatus literally anything that has in some way the capacity to capture, orient, determine, intercept, model, control, or secure the gestures, behaviors, opinions, or discourses of living beings." The resulting effect of this working of apparatuses on living beings are, "between these two, as a third class, subjects." Agamben calls "a subject that which results from the relation and, so to speak, from the relentless fight between living beings and apparatuses."

Like in Althusser's concept of interpellation, subjectivation here emerges as a product of the dispositif at work. Adopting Agamben's diagram, we can deduce that if the modern "subject" wants to address the "apparatus," if it wants to speak to or about the apparatus and its workings, it will in all likelihood choose the term "machine".

The "machine" is not a technological other, but it is, like the "subject," a product of the "apparatus," named and constructed by the subject. The subject speaks of the machine as though it were on the outside, an other, yet it is the subject's technological doppelgänger, an apparative sibling, a complementary product of the workings of the apparatus.

This latter diagram is useful for explaining the awkward relationship that people, as human subjects, maintain with machines. It makes it clear that "machine" is not a technical category, but a social one, and that it is not a descriptive term for a concrete class of technical items, but a symbolic concept. The diagram also elucidates that it is always a subject that speaks of a "machine"; designating and addressing the "machine" is a projection in the direction of the very apparatus that brings forth the speaking subject.

\section{THE MACHINE AS MYTH}

On the level of human communication, of culture, the machine operates as a myth. Not in the polemical sense of an untrue story, but rather in the functional sense of the term. Very generally 
speaking, a myth is a form of narrative that is engrained in a culture. A myth is collectively held, and repeated and affirmed, and it is powerful. Until the 1960s, the notion of myth was generally reserved for the belief systems of ancient and of non-Western cultures, whereas since the ideological critiques of semiotics and structuralism in the 1960s, and not least through the analyses of popular cultural items offered by Roland Barthes in Mythologies (1957), the belief systems of Western modernity have been shown to also be based on such mythological narratives.

According to the German philosopher Hans Blumenberg, myths are characterised by a narrative kernel which is both variable and, more importantly, of extended continuity (Blumenberg 1979). A myth is an articulation of ignorance, resulting in fear or hope, and a way to make sense of the world, whether in the face of the forces, and the supposed agency, of nature, or, in modernity, also addressing the agency of technics and its spiritual (or ideological) dimensions, like rationality, functionality, or necessity.

A crucial reference text for a discussion of the machine as myth is social historian Lewis Mumford's, The Myth of the Machine (1966/1970). Mumford claims that the conceptual power of the machine myth is not a modern phenomenon, but that it harks back to human experiences in ancient and pre-historic times. For Mumford, the notion of the machine originates from an ancient order of ritual, an order which humans developed as a form of self-protection to compensate for the huge psychic pressures exerted by their hostile natural environment. In the contemporary machine myth, there persist forms of unformed, unorganised phenomena of the human spirit that in the modern period have not disappeared but grown stronger by being channeled into science and technics.

Mumford's passionate analysis is driven by his frustration about the fact that this myth has resulted in a continued connection of excessive power and productivity with equally excessive violence and destruction. Echoing the worries of Alfred Barr and Bruno Munari, Mumford envisions that, as a result of the emergence of the modern mega-techniques, humans will not act as autonomous individuals, but they will become passive, aimless and machinedependent animals whose true functions are passed over to machines, or strictly limited and controlled in favour of depersonalised and collective organisations.

Mumford is convinced that the modern technological process is neither natural, nor unchangeable, nor did it come about without human intervention. His goal is therefore to shrug off the myth of the mega-machine, and for his readers to understand, and where necessary, to change the course of contemporary technics.

\section{THE MYTH OF THE MACHINE}

It is now possible to identify the narrative kernel of the myth of the machine. As a comparison, consider the myth of Oedipus. Whenever the name Oedipus is mentioned, the whole complex narrative of the myth, its proponents and tragic twists, is envoked. In the same way, the whole of the myth of the machine is brought into play, whenever the term "machine" is used. It goes something like this.

\section{This is the myth of the machine.}

There is a man-made object. It can be a physical device, or a symbolical representation, related to technics by association or indexicality.

It is composed of technical elements, it has moving parts, and it has a function which it performs by repetitive movement. And it exhibits a certain formal beauty.

It is made to function automatically and independent of direct and continuous human intervention.

Over time, the object attains an increasing degree of autonomy.

It may provide interfaces for human interaction. These, however, do not determine the functionality: the human interaction can be replaced by technical elements, or by other machines. The interfaces offer the human an illusion of control which can be overridden by the machine. The interfaces are only there to appease the humans, for their play and enjoyment, or for human-machine conviviality.

The autonomy of the machine becomes threatening for humans who, fearfully, struggle not for their lives, but for self-determination. The threat posed by the machine is existential, but not lethal.

The narrative tends not to have an ending. If it has one, then the story ends well for the humans.

Like other myths, the myth of the machine can be varied, but it cannot be told completely differently. It is always this one story of something man-made being functional and then gaining a dangerous, non-lethal form of autonomy. - Sarah I. Johnston proposes the term "plurimedial" for this characteristic aspect of the myth as deriving from a variety of sources and versions, whereas she uses the term "accretive" to refer to the composite way in which a myth takes shape in the mind of a particular individual (Johnston 2019).

Consider the example of a loom. It is a technical device, and it is used for weaving textiles. When a person beholds the loom and says, "ah, a 
machine," he or she calls up the myth of the machine and at once the entire narrative framing comes into play, its blueprint, its construction, its degrees of freedom, and the inherent threat. The ways in which the loom is then treated, in the realm of the myth, is different from how it is treated when viewed as a weaving device.

What we can learn from this mythological understanding of the "machine" is that the modern conception of self is imbricated with technology in this particular way. There really is no "machine" outside this narrative, and whenever the word "machine" is uttered, this figure of speech constructs the relationship between human and the technical object within that mythical structure, as binary, antagonistic, and ontologically differentiated. In contrast, this proposal seeks to make it possible to, finally, speak about the myth of the machine, and not "in" or "through" this myth.

\section{BACHELOR MACHINE AND CYBORG}

Two among many inflections of the twentiethcentury myth of the machine are the technological myths of the Bachelor Machine, and the Cyborg. They highlight, moreover, the gendered nature of the machine myth, and point to the emancipatory potential of developing alternative mythological narratives.

The myth of the Bachelor Machine was "isolated" by Michel Carrouges and elaborated in his publication on Les machines célibataires of 1954 . Carrouges describes it and traces its variations in a number of literary and artistic examples, from Marcel Duchamp and Alfred Jarry to Franz Kafka and Edgar Allan Poe. According to Carrouges (1975), who figures as its mythographer (Le Bot 1975), the Bachelor Machine is not a particular type of device, but it is a formal structure that articulates human and technics, life and death, male and female aspects.

A more recent narrative about the encounter of human and technology, is the feminist myth of the Cyborg that was described and elaborated by Donna Haraway in the mid-1980s (Haraway 1991).

By the late twentieth century, our time, a mythic time, we are all chimeras, theorized and fabricated hybrids of machine and organism. In short, we are cyborgs. The cyborg is our ontology; it gives us our politics.

The Cyborg myth is designed by Haraway as a deliberate counter-narrative to aspects of the machine myth, suggesting a re-evaluation of the relationship especially (but not only) of women towards technology.
The machine is not an it to be animated, worshipped and dominated. The machine is us, our processes, an aspect of our embodiment. We can be responsible for machines; they do not dominate or threaten us.

An important lesson to be learned from the case of the Cyborg myth is that a current mythology is something that is, at the same time, given, and that can be transformed and rewritten. This dialectic of affirmation and transformation is performed in every instance when a certain myth is narrated.

One important route for reconstructing socialistfeminist politics is through theory and practice addressed at the social relations of science and technology, including crucially the systems of myth and meanings structuring our imaginations. The cyborg is a kind of disassembled and reassembled, postmodern collective and personal self. This is the self feminists must code.

The social and historical context into which Haraway's Cyborg myth is embedded, are the postmodern and "scary new networks" of an "informatics of domination", a techno-logical form of power which equally holds potentials for emancipation, and potentials of submission and disempowerment.

In contrast to the Cyborg, the notion of the machine is tied to an older, modernist understanding of the human subject, and to an apparative technical paradigm which itself is currently being supplanted by a techno-sphere of networked and ubiquitous systems. This might result in a transformation of a Cyborgian subjectivity that will no longer be constructed in opposition to technics, but that engenders a subject which experiences itself as an integrated part of such technical systems. The machine myth intends (Barthes) an affective blackboxing of technology, giving us reason to break through its conceptual frame.

This will make more pressing the question of engineering, of building and of reconstructing technical systems. I wonder whether Haraway has gone far enough in equipping the Cyborg with the means and desires to re-engineer the technologos, and to devise alternatives to the "informatics of domination". Only at the very end of the Cyborg Manifesto, Haraway makes a brief mention of the need to develop a powerful, heterogenic way of speaking and doing technics, of building and destroying machines and identities.

\section{RESISTANCES}

Artistic productions have a special connection with the theme of myth-making, and un-making. To a large extent, mythology is a literary genre, and the myths of modern and postmodern technology - 
including that of the Cyborg - have often been analysed with reference to science fiction films and literature. Similarly, the story that one can tell about the history of machine art is one of the making and the un-making of the machine myth.

The urgency for such a re-engineering of the techno-logos is highlighted by the discourse on artificial intelligence, which is only another, debilitating iteration of the machine myth, sign of the blockade against a critical and emacipatory discourse on technics. What is the anthropological effect of a narrative that pitches human intelligence against machine intelligence, and that posits them not only as homologous, but that also - based on the assumption of "Moore's Law" - implies an inevitable, eventual supersession of human intellectual leadership by machine-based pattern recognition and decision-making systems?

An artwork engaged in the reproduction of the machine myth is US-American artist Trevor Paglen's image series, Adversarially Evolved Hallucinations (2017), created from a combination of image recognition software systems. The outcome are eerie, surreal and mostly abstract images that contain human-recognisable elements like eyes, human limbs, or plants, positioned in non-realistic constellations and surrounded by nonrepresentational, painterly modulated areas of intense colours. In their production, constellations of algorithms in neural networks, or "artificial intelligence" systems (so-called "generative adversarial networks, GAN"), are trained with data sets and then deployed to generate a visual output that resembles and recombines elements of the training data sets, without being tied to the visual codes of human recognisability and naturalism.

Paglen's proposition that these are "images made by computers for themselves", only holds if one ignores the fact that the visual training data are themselves selected by humans on the basis of categories like monstrosity and uncanniness, the resulting images thus merely providing an algorithmically distorted mirror of the visual iconography of fear. Paglen's image-generating "enhanced pattern recognition" system (Hunger 2017) does, however, underscore the illusion of a "dreaming machine", an illusion that seeks to amplify fears about a potentially subjective and autonomous machine. Like the myth of the machine, the myth of "artificial intelligence" is here evoked in order to affirm an existentially dangerous confrontation of human and technics.

There are, however, also alternative examples of how, in the aftermath of the machine myth, the techno-logos is being imagined and projected by artists, offering indications of what interventions into the technological transformation - maybe "resistances" - could look like.
One is more openly oppositional, and it inherits the humorous obstinacy and celebration of dysfunctionality from Bruno Munari and Jean Tinguely. We can recognise their attitude in the work of Herwig Weiser, whose installations deconstruct the techno-logics of the moving image, of film and of sculpture by compressing them into objects that are apparatus, medium, display and sculpture at the same time, their operation taking the shape of a transitional, uncalculable event (Marburger 2018). Weiser offers an alternative, speculative techno-logics. He allows his work to traverse, to pass through the polymorphous materialities of contemporary technics - making the machinic phylum roam beyond the bounds of engineering, building devices that transgress their technological determinations.

A second line of critical work is opened up by notions that have also inspired the alternative myth of the Cyborg: in particular, these are a conception of the "machine" not as one, but as many, as a fabric through which we travel and which we continuously weave, unravel and recompose.

Technics is here not conceived as an ontological other, but as the matrix of both subjectivity and agency - true to Haraway's dictum, "weaving is for oppositional cyborgs" (Haraway 1991).

This trajectory is laid out by the work of the late Seiko Mikami, a Japanese artist whose interactive installations span the period from the early 1990s to around 2010. Her last major work, Desire of Codes (2010), speculates about encounters with forms of artificial intelligence. In the installation, the imagined technical entity is not represented in a single form, but is distributed across four instances with a multiplicity of technical input and output devices - six robotic arms observing and reflecting individual visitor's movements; a wall of ninety small robotic units that follow and confront several visitors like a swarm; a multi-facetted display that mixes images from local and translocal, current and past visual sources; and a screen display that suggests the synaptic activities in the database which relays the visual data input and output.

While this technical entity is conceived as a dispersed matrix - for which Mikami has also imagined various paranoiac and dream-like "states of machine mind" -, an earlier work which Mikami realised together with artist-architect Sota Ichikawa, entitled gravicells - gravity and resistance (2004), articulates the systemic and eco-logical relations and interactions between technical, natural, and human actors. The work correlates the physical presence of the visitors with the gravitational forces of the Earth and of communication satellites.

Significantly, the question of human subjectivity is not an issue here. The exhibition visitor is 
represented only as an area of gravitational force, and walking through the installation is a mere inscription of a body-object into a force field that provides no identitarian feedback.

gravicells suggests a scenario in which gravitation and the mutual influence of different objects bodies, satellites, the Earth - form a dynamic system. It requires the self-inscription of the interacting human body into an interdependent, techno-ecological system. Here, technology is not an alien other, but a mode of existence, of being in the world. gravicells thus dispels the concept of a "machine" in favor of a system that aesthetically integrates technical, human, and natural elements and treats them on a single plane. - It should be a matter of ethical debate whether such an inscription into a matrix of eco-technological relations is desirable, and in how far the gravicells matrix is imbued with the "informatics of domination" that also constitutes the world of Haraway's Cyborg. In any case, however, such an eco-technological environment - or apparatus - requires us to imagine ourselves beyond the binary opposition into which the myth of the machine places us.

Similar to the Cyborg myth, works like those by Seiko Mikami encourage us to accept our hybrid origins, without seeking purity and segregation. On the contrary, we should strive to develop the emancipatory potentials of blending and - like the queer and cyberfeminist thinker Allucquére Rosanne Stone (1996) - surrender, together with the binary opposition of "man" or "woman," also the "either/or" in the relationship between humans and technics.

The ideas in this text were first presented in a talk at the conference "Politics of the Machines - Art and After", EVA-Copenhagen, Aalborg University, on 15 May 2018.

\section{REFERENCES}

Agamben, G. (2009) What Is an Apparatus? (2006). In What Is an Apparatus? and Other Essays. Stanford University Press, Stanford, CA.

Assmann, J. and A. (1998) Mythos. In H. Cancik e.a. (eds.), Handbuch religionswissenschaftlicher Grundbegriffe. Kohlhammer, Stuttgart.

Barthes, R. (2009) Mythologies (1957). Vintage, London.

Blumenberg, H. (1985) Work on Myth (1979). MIT Press, Cambridge, MA.

Blumenberg, H. (2010) Paradigms for a Metaphorology (1960). Cornell University Press, Ithaca, NY.
Broeckmann, A. (2016) Machine Art in the Twentieth Century. MIT Press, Cambridge, MA.

Burckhardt, M. (1999) Der Geist der Maschine.

Campus, Frankfurt/M.

Burckhardt, M. (2002) Das Monster und seine telematische Guillotine. In K. P. Dencker (ed.), Interface 5- Die Politik der Maschine. Hans Bredow Institut, Hamburg.

Carrouges, M. (1975) Directions for Use. In H. Szeemann (ed.), The Bachelor Machines. Rizzoli, New York.

Deleuze, G., and F. Guattari (2004) Anti-Oedipus (1972). Continuum, London.

Dotzler, B. (2005) Medeamaschinen. In: Paragrana, 14.2, 119-144.

Foucault, M. (1970) The Order of Things (1966). Pantheon, London.

Habermas, J. (1970) Technology and Science as 'Ideology'. In Toward a Rational Society. Beacon Press, Boston.

Haraway, D. (1991) A Cyborg Manifesto: Science, Technology, and Socialist-Feminism in the Late Twentieth Century (1985). In Simians, Cyborgs, and Women. Free Association Books, London.

Hunger, F. (2017) Artificial Des-Intelligence or Why machines will not take over the world. At least not now. http://databasecultures.irmielin.org/artificialdes-intelligence/ (retrieved 5 June 2018).

Johnston, S. I. (2019) The Story of Myth. Harvard University Press, Cambridge, MA.

Le Bot, M. (1975) The Myth of the Machine. In H. Szeemann (ed.), The Bachelor Machines. Rizzoli, New York.

Marburger, M. R. (ed.) (2018) Weiser. Edition_, Cologne.

Marshall, J. J. (2012) Machine Art, 1934. University of Chicago Press, Chicago, IL.

Mumford, L. (1967-1970) The Myth of the Machine. 2 Vols. Harcourt Brace Jovanovich, New York.

Reck, H. U., J. Clair and H. Szeemann (eds.) (1999) Junggesellenmaschinen. Springer, Vienna.

Schmidgen, H. (2004) Thinking technological and biological beings: Gilbert Simondon's philosophy of machines. Unpubl. lecture manuscript.

Stone, A. S. (1996) The War of Desire and Technology at the Close of the Mechanical Age. MIT Press, Cambridge, MA. 